\title{
Exposure to Music and Noise During Pregnancy Influences Neurogenesis and Thickness in Motor and Somatosensory Cortex of Rat Pups
} \author{
Yun-Hee Sung ${ }^{4}$, Chang-Ju Kim², Khae-Hawn Kim

\begin{abstract}
Department of Urology, Gachon University Gil Medical Center, Gachon University, Incheon;
${ }^{1}$ Department of Urology, Gachon University of Medicine and Science, Incheon;

${ }^{2}$ Department of Physiology, Kyung Hee University School of Medicine, Seoul;

${ }^{3}$ Department of Psychiatry, Gangneung Asan Hospital, University of Ulsan College of Medicine, Gangneung;
\end{abstract} \\ ${ }^{4}$ Department of Physical Therapy, Kyungnam University, Changwon, Korea
}

Chang-Hee Kim, Sang-Chul Lee, Je Wook Shin ${ }^{1}$, Kyung-Jin Chung, Shin-Ho Lee², Mal-Soon Shin², Sang-Bin Baek ${ }^{3}$,

Purpose: Prenatal environmental conditions affect the development of the fetus. In the present study, we investigated the effects of exposure to music and noise during pregnancy on neurogenesis and thickness in the motor and somatosensory cortex of rat pups. Methods: The pregnant rats in the music-applied group were exposed to $65 \mathrm{~dB}$ of comfortable music for 1 hour, once per day, from the 15th day of pregnancy until delivery. The pregnant rats in the noise-applied group were exposed to $95 \mathrm{~dB}$ of sound from a supersonic sound machine for 1 hour, once per day, from the 15th day of pregnancy until delivery. After birth, the offspring were left undisturbed together with their mother. The rat pups were sacrificed at 21 days after birth.

Results: Exposure to music during pregnancy increased neurogenesis in the motor and somatosensory cortex of rat pups. In contrast, rat pups exposed to noise during pregnancy showed decreased neurogenesis and thickness in the motor and somatosensory cortex.

Conclusions: Our study suggests that music and noise during the developmental period are important factors influencing brain development and urogenital disorders.

Keywords: Music; Noise; Neurogenesis; Motor cortex; Somatosensory cortex

\section{INTRODUCTION}

Prenatal environmental conditions affect the development of the fetus. Various physical and emotional stresses during pregnancy induce neonatal abnormalities and delay the development of motor function in the offspring [1,2]. In late gestation, the fetus can hear sounds from outside the mother [3].

Music affects the development of biological systems [4,5]. Listening to music enhances learning ability and cognitive function [6], reduces blood pressure [7], and ameliorates symptoms of epilepsy, Parkinson disease, and senile dementia [8-10]. Exposure to music during pregnancy enhances the brain develop- ment of the fetus, improves spatial-temporal learning in neonatal rats, and induces rapid advances in motor ability such as sitting and walking in infants $[6,11]$.

In contrast, noise is a devastating environmental stress that affects pregnant mammals and their fetuses. Noise causes psychological and psychosomatic problems [12], decreases newborn body weight, and induces stillbirths, fetal teratogenesis, and abortion $[13,14]$. Exposure to noise during pregnancy may disturb postnatal brain development and may also impair cognitive function [15].

The cerebral cortex is the outermost sheet of neural tissue in the cerebrum. The cerebral cortex plays a key role in memory,
Corresponding author: Khae-Hawn Kim

Department of Urology, Gachon University Gil Medical Center,

Gachon University, 21 Namdong-daero 774beon-gil, Namdong-gu,

Incheon 405-760, Korea

$\mathrm{Tel}+82-32-460-3331 / \mathrm{Fax}+82-32-460-8340$

E-mail kimcho99@gilhospital.com

Submitted: September 9, 2013 / Accepted after revision: September 24, 2013
This is an Open Access article distributed under the terms of the Creative Commons Attribution Non-Commercial License (http://creativecommons.org/licenses/by-nc/3.0/) which permits unrestricted non-commercial use, distribution, and reproduction in any medium, provided the original work is properly cited.

Copyright (C) 2013 Korean Continence Society 
attention, perceptual awareness, thought, language, and consciousness. It is divided into the somatosensory, motor, and association cortex. The somatosensory cortex receives sensory inputs; meanwhile, the motor cortex controls the movement of muscles. In general, the somatosensory cortex is thinner and the motor cortex is thicker [16]. The cerebral cortex, including the motor and somatosensory cortex, is composed of six layers. Layer I (molecular layer) is composed mostly of fibers. Layer II (external granule layer) is very dense and contains small granular cells and small pyramidal cells. Layer III (external pyramidal layer) contains pyramidal cells arranged in row formation. Layer IV (internal granule layer) is thin, but its cell structure is the same as that of the external granular layer. Layer V (internal pyramidal layer) contains small granular cells, large pyramidal cells, as well as the cell bodies of some association fibers. The association fibers that originate here form two large tracts. Layer VI is also known as the multiform layer. The individual layers in the cerebral cortex have different roles and are of varying thickness.

Previously, the impact of music and noise during pregnancy on the offspring's learning ability in relation to hippocampal neurogenesis was reported [17]. However, the influence of music and noise during pregnancy on neurogenesis and thickness in the motor and somatosensory cortex has not been described. In the present study, we investigated the effects of music and noise during pregnancy on neurogenesis and thickness in the motor and somatosensory cortex of rat pups.

\section{MATERIALS AND METHODS}

\section{Animals}

The experimental procedures were performed in accordance with the guidelines of the National Institutes of Health and the Korean Academy of Medical Sciences. Sprague-Dawley male rats $(250 \pm 10 \mathrm{~g}, 12$ weeks old) and Sprague-Dawley female rats ( $180 \pm 10 \mathrm{~g}, 8$ weeks old) were used in this study. Female rats $(n=20)$ were allowed to mate with male rats $(n=20)$ for 24 hours. One day after mating, the female rats were separated from the male rats and housed individually in plastic cages at a controlled temperature $\left(20^{\circ} \mathrm{C} \pm 2^{\circ} \mathrm{C}\right)$ and a light-dark cycle of 12 hours of light and 12 hours of darkness (lights on from 0700 to 1900). Food and water were made available ad libitum.

After confirmation of pregnancy on day 14 after mating, the pregnant rats were randomly divided into three groups: the control group, the music-applied group, and the noise-applied group ( $\mathrm{n}=5$ in each group). From the 15 th day of pregnancy until delivery, all pregnant rats were subcutaneously injected with 100 mg/kg 5-bromo-2'-deoxyuridine (BrdU; Sigma Chemical Co., St. Louis, MO, USA) once per day 30 minutes before the start of the experimental treatment until delivery. The pregnant rats in the music-applied group were exposed to $65 \mathrm{~dB}$ of comfortable music for 1 hour, once per day until delivery. The pregnant rats in the noise-applied group were exposed to $95 \mathrm{~dB}$ of sound from a supersonic sound machine for 1 hour, once per day until delivery. The pregnant rats in the control group were left undisturbed. After birth, the offspring were left undisturbed together with their mothers. The rat pups were sacrificed at 21 days after birth.

\section{Tissue Preparation}

Brain tissue was prepared according to a previously described method [18]. The animals were fully anesthetized with Zoletil $50(10 \mathrm{mg} / \mathrm{kg}$, intraperitoneally; Vibac Laboratories, Carros, France), transcardially perfused with $50 \mathrm{mM}$ phosphate-buffered saline (PBS), and fixed with freshly prepared solution consisting of $4 \%$ paraformaldehyde in $100 \mathrm{mM}$ phosphate buffer ( $\mathrm{pH}$ 7.4). The brains were then removed, postfixed in the same fixative overnight, and transferred into a $30 \%$ sucrose solution for cryoprotection. Coronal sections of $40 \mu \mathrm{m}$ thickness were made by using a freezing microtome (Leica, Nussloch, Germany).

\section{Immunohistochemistry for BrdU}

For the detection of newly generated cells in the cerebral cortex (including the motor cortex and the somatosensory cortex), BrdU immunohistochemistry was performed as previously described $[17,19]$. The sections were permeabilized by incubating them with $0.5 \%$ Triton X-100 in PBS for 20 minutes, treated with $50 \%$ formamide, $2 \times$ standard saline citrate at $65^{\circ} \mathrm{C}$ for 2 hours, denatured in $2 \mathrm{~N} \mathrm{HCl}$ at $37^{\circ} \mathrm{C}$ for 30 minutes, and then rinsed twice in $100 \mathrm{mM}$ sodium borate ( $\mathrm{pH}$ 8.5). Subsequently, the sections were incubated overnight at $4^{\circ} \mathrm{C}$ with BrdU-specific mouse monoclonal antibody (1:600; Roche, Mannheim, Germany). The sections were then washed three times with PBS and incubated for 1 hour with a biotinylated mouse secondary antibody (1:200; Vector Laboratories, Burlingame, CA, USA). Then, the sections were incubated for another 1 hour with avidin-peroxidase complex (1:100; Vector Laboratories). For the visualization of $\mathrm{BrdU}$, the sections were incubated with $50 \mathrm{mM}$ Tris- $\mathrm{HCl}$ (pH 7.6) containing 0.02\% 3,3'-diaminobenzidine tet- 
rahydrochloride (DAB) containing nickel chloride $(40 \mathrm{mg} / \mathrm{mL})$ and $0.03 \%$ hydrogen peroxide for 5 minutes. After BrdU-specific staining, counter-staining was performed on the same sections by using a mouse antineuronal nuclei antibody (1:300; Chemicon International, Temecula, CA, USA). The sections were washed three times with PBS, incubated for 1 hour with a biotinylated antimouse secondary antibody, and processed with the VECTASTAIN ABC Kit (Vector Laboratories). For staining, the sections were reacted with $0.02 \% \mathrm{DAB}$ and $0.03 \%$ hydrogen peroxide in $50 \mathrm{mM}$ Tris- $\mathrm{HCl}$ ( $\mathrm{pH}$ 7.6) for 5 minutes, and the sections were finally mounted onto gelatin-coated slides. The slides were air dried overnight at room temperature, and coverslips were mounted by using Permount (Fisher Scientific, Bridgewater, NJ, USA).

\section{Data Analysis}

All data were analyzed by using the SPSS ver. 12.0 (SPSS Inc., Chicago, IL, USA). The data were expressed as the mean \pm standard error of the mean. For comparison among groups, one-way analysis of variance and Duncan post hoc test were performed and differences were considered statistically significant at $\mathrm{P}<0.05$.

\section{RESULTS}

\section{Influence of Prenatal Music and Noise on Neurogenesis in the Motor Cortex of Rat Pups}

The number of BrdU-positive cells in motor cortex layer I was $15.08 \pm 2.05$ in the control group, $16.29 \pm 2.38$ in the music-applied group, and $11.29 \pm 1.52$ in the noise-applied group. The number of BrdU-positive cells in motor cortex layers II and III was $168.00 \pm 11.44$ in the control group, $195.97 \pm 17.18$ in the music-applied group, and $86.04 \pm 16.30$ in the noise-applied group. The number of BrdU-positive cells in motor cortex layer IV was $51.00 \pm 4.53$ in the control group, $71.32 \pm 7.20$ in the music-applied group, and $35.86 \pm 6.62$ in the noise-applied group. The number of BrdU-positive cells in motor cortex layer $\mathrm{V}$ was $52.08 \pm 6.16$ in the control group, $99.97 \pm 16.25$ in the music-applied group, and $58.46 \pm 7.77$ in the noise-applied group. The number of BrdU-positive cells in motor cortex layer VI was $85.39 \pm 10.43$ in the control group, $103.24 \pm 14.06$ in the musicapplied group, and $68.11 \pm 18.00$ in the noise-applied group. The total number of BrdU-positive cells in the motor cortex was $371.56 \pm 29.29$ in the control group, $486.79 \pm 47.21$ in the musicapplied group, and $259.75 \pm 43.98$ in the noise-applied group.
Application of music to pregnant rats increased neurogenesis in the motor cortex of rat pups $(\mathrm{P}<0.05)$. In contrast, application of noise to pregnant rats reduced neurogenesis in the motor cortex of rat pups $(\mathrm{P}<0.05)$ (Fig. 1).

\section{Influence of Prenatal Music and Noise on Layer Thickness in the Motor Cortex of Rat Pups}

The thickness of motor cortex layer I was $0.175 \pm 0.022 \mathrm{~mm}$ in the control group, $0.138 \pm 0.034 \mathrm{~mm}$ in the music-applied group, and $0.124 \pm 0.038 \mathrm{~mm}$ in the noise-applied group. The thickness of motor cortex layers II and III was $0.308 \pm 0.012 \mathrm{~mm}$ in the control group, $0.310 \pm 0.012 \mathrm{~mm}$ in the music-applied group, and $0.279 \pm 0.007 \mathrm{~mm}$ in the noise-applied group. The thickness of motor cortex layer IV was $0.185 \pm 0.008 \mathrm{~mm}$ in the control group, $0.154 \pm 0.007 \mathrm{~mm}$ in the music-applied group, and $0.148 \pm 0.009 \mathrm{~mm}$ in the noise-applied group. The thickness of motor cortex layer $\mathrm{V}$ was $0.283 \pm 0.009 \mathrm{~mm}$ in the control group, $0.272 \pm 0.002 \mathrm{~mm}$ in the music-applied group, and $0.251 \pm 0.007 \mathrm{~mm}$ in the noise-applied group. The thickness of motor cortex layer VI was $0.328 \pm 0.011 \mathrm{~mm}$ in the control group, $0.329 \pm 0.013 \mathrm{~mm}$ in the music-applied group, and $0.314 \pm 0.009 \mathrm{~mm}$ in the noise-applied group. The total thickness of the motor cortex was $1.277 \pm 0.034 \mathrm{~mm}$ in the control group, $1.204 \pm 0.034 \mathrm{~mm}$ in the music-applied group, and $1.116 \pm 0.018 \mathrm{~mm}$ in the noise-applied group.

Application of music to pregnant rats exerted no significant effect on the motor cortex thickness of the rat pups $(\mathrm{P}<0.05)$. In contrast, application of noise to pregnant rats decreased thickness in the motor cortex of rat pups $(\mathrm{P}<0.05)$ (Fig. 1).

\section{Influence of Prenatal Music and Noise on Neurogenesis in the Somatosensory Cortex of Rat Pups}

The number of BrdU-positive cells in somatosensory cortex layer I was $21.33 \pm 2.17$ in the control group, $28.37 \pm 4.20$ in the music-applied group, and $18.71 \pm 3.41$ in the noise-applied group. The number of BrdU-positive cells in somatosensory cortex layers II and III was $317.22 \pm 27.98$ in the control group, 403.74 \pm 35.44 in the music-applied group, and $232.14 \pm 54.85$ in the noise-applied group. The number of BrdU-positive cells in somatosensory cortex layer IV was $98.94 \pm 10.88$ in the control group, $127.00 \pm 14.26$ in the music-applied group, and $98.93 \pm$ 18.41 in the noise-applied group. The number of BrdU-positive cells in somatosensory cortex layer V was $82.67 \pm 8.99$ in the control group, $156.63 \pm 22.51$ in the music-applied group, and $112.21 \pm 20.16$ in the noise-applied group. The number of $\mathrm{Br}$ - 

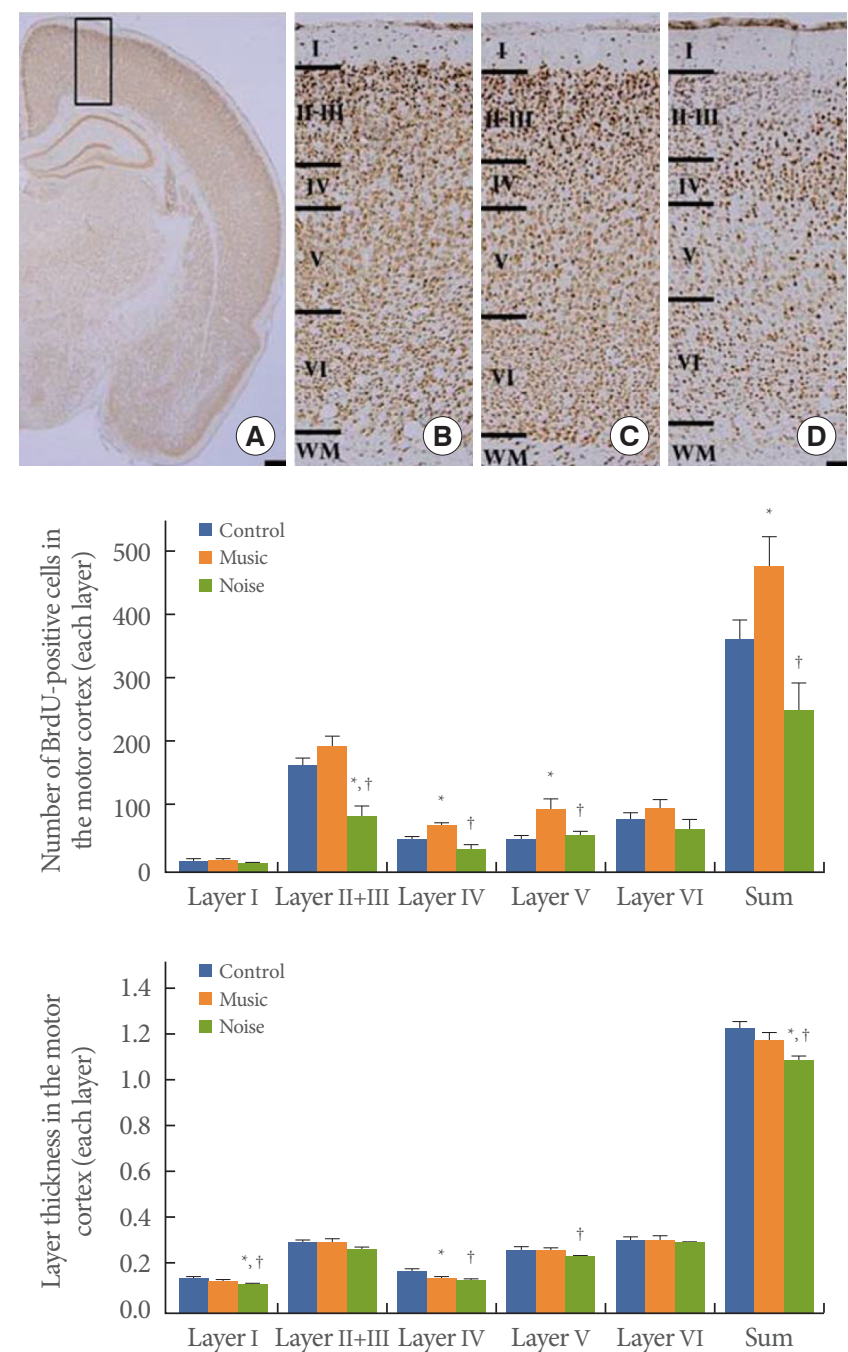

Fig. 1. Influence of prenatal music and noise on neurogenesis and thickness in the motor cortex of rat pups. Upper: (A) Representation of the examined motor cortex (open square at the dorsomedial portion of the cortex), (B) control group, (C) music-applied group, (D) noise-applied group. The scale bar in A is $25 \mu \mathrm{m}$ and the scale bar in B-D is $100 \mu \mathrm{m}$. Middle: Neuronal populations in each cortical layer of the motor cortex. Lower: Thickness in each cortical layer of the motor cortex. The data present the mean \pm standard error of the mean. WM, white matter. ${ }^{\star} \mathrm{P}<0.05$ compared with the control group. ${ }^{\dagger} \mathrm{P}<0.05$ compared with the music-applied group.

dU-positive cells in somatosensory cortex layer VI was $140.56 \pm$ 17.67 in the control group, $210.53 \pm 35.48$ in the music-applied group, and $123.14 \pm 27.51$ in the noise-applied group. The total number of BrdU-positive cells in the somatosensory cortex was $660.72 \pm 58.90$ in the control group, $926.26 \pm 93.44$ in the music-
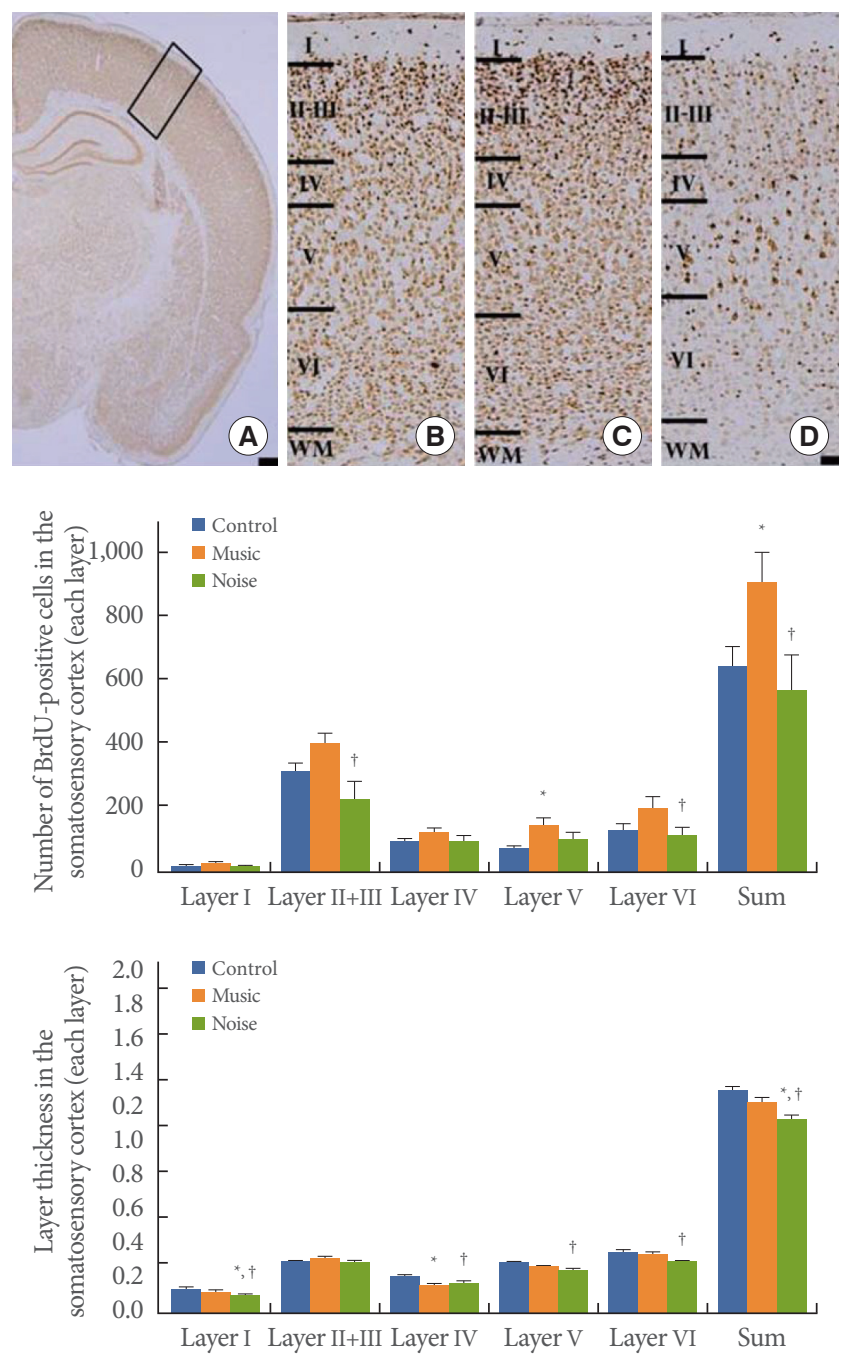

Fig. 2. Influence of prenatal music and noise on neurogenesis and thickness in the somatosensory cortex of rat pups. Upper: (A) Representation of the examined somatosensory cortex (open square at the dorsolateral portion of the cortex), (B) control group, (C) music-applied group, (D) noise-applied group. The scale bar in A is $25 \mu \mathrm{m}$ and the scale bar in B-D is $100 \mu \mathrm{m}$. Middle: Neuronal populations in each individual cortical layer of the somatosensory cortex. Lower: Thickness in each individual cortical layer of the somatosensory cortex. The data present the mean \pm standard error of the mean. WM, white matter. ${ }^{\star} \mathrm{P}<0.05$ compared with the control group. ${ }^{\dagger} \mathrm{P}<0.05$ compared with the music-applied group.

applied group, and 585.14 \pm 110.63 in the noise-applied group.

Application of music to pregnant rats increased neurogenesis in the somatosensory cortex of rat pups $(\mathrm{P}<0.05)$. In contrast, application of noise to pregnant rats reduced neurogenesis in the somatosensory cortex of rat pups $(\mathrm{P}<0.05)$ (Fig. 2). 


\section{Influence of Prenatal Music and Noise on Layer Thickness in the Somatosensory Cortex of Rat Pups}

The thickness of somatosensory cortex layer I was $0.141 \pm 0.006$ $\mathrm{mm}$ in the control group, $0.129 \pm 0.006 \mathrm{~mm}$ in the music-applied group, and $0.103 \pm 0.007 \mathrm{~mm}$ in the noise-applied group. The thickness of somatosensory layers II and III was $0.294 \pm 0.009$ $\mathrm{mm}$ in the control group, $0.318 \pm 0.015 \mathrm{~mm}$ in the music-applied group, and $0.295 \pm 0.013 \mathrm{~mm}$ in the noise-applied group. The thickness of somatosensory cortex layer IV was $0.215 \pm$ $0.009 \mathrm{~mm}$ in the control group, $0.169 \pm 0.008 \mathrm{~mm}$ in the musicapplied group, and $0.178 \pm 0.015 \mathrm{~mm}$ in the noise-applied group. The thickness of somatosensory cortex layer $V$ was $0.297 \pm 0.007$ $\mathrm{mm}$ in the control group, $0.273 \pm 0.012 \mathrm{~mm}$ in the music-applied group, and $0.261 \pm 0.009 \mathrm{~mm}$ in the noise-applied group. The thickness of somatosensory cortex layer VI was $0.359 \pm 0.016$ $\mathrm{mm}$ in the control group, $0.351 \pm 0.018 \mathrm{~mm}$ in the music-applied group, and $0.305 \pm 0.013 \mathrm{~mm}$ in the noise-applied group. The total thickness of the somatosensory cortex was $1.305 \pm$ $0.023 \mathrm{~mm}$ in the control group, $1.241 \pm 0.035 \mathrm{~mm}$ in the musicapplied group, and $1.142 \pm 0.049 \mathrm{~mm}$ in the noise-applied group. Application of music to pregnant rats exerted no significant effect on thickness in the somatosensory cortex of rat pups $(\mathrm{P}<$ 0.05). In contrast, application of noise to pregnant rats decreased thickness in the somatosensory cortex of rat pups $(\mathrm{P}<0.05)$ (Fig. 2).

\section{DISCUSSION}

The development of the fetus is beset by a complex set of environmental influences. It is generally accepted that music is an effective strategy for prenatal education. Rapid development of motor ability, such as sitting and walking, has been observed in infants exposed to music during pregnancy [20]. Exposure to music during pregnancy has also been shown to facilitate fetal growth and brain development [21]. In chicks, exposure to prenatal music enhances synaptic protein expression in the brainstem auditory nuclei and increases the size and the number of neurons in the forebrain auditory association area [11]. Exposure to music during pregnancy in rat pups increases hippocampal neurogenesis and then enhances their spatial learning ability [17].

In the present results, exposure to music during pregnancy increased neurogenesis in the motor and somatosensory cortex of rat pups. In detail, the music increased neurogenesis of layer $\mathrm{IV}$ and layer $\mathrm{V}$ in the motor cortex and of layer $\mathrm{V}$ in the so- matosensory cortex. Music exerted no significant effect on layer thickness in the motor or somatosensory cortex.

Prenatal stresses are known to influence brain development and behavior in the affected fetuses [1]. Exposure to noise during pregnancy retards postnatal brain development and also impairs cognitive function [15]. Prenatal stresses during pregnancy induce retardation of growth and impaired proliferation and differentiation of neurons [22]. These results induce deficits in cognitive function with neurological and behavioral abnormalities of offspring [2]. Children born from mothers under stress during pregnancy have a higher risk of developing sensorineural hearing loss [23]. Prenatal stress is closely associated with cognitive, behavioral, physical, and emotional problems [24-27]; autism [28,29]; and attention-deficit hyperactivity disorder [30,31]. Exposure to noise during pregnancy causes growth retardation, decreases neurogenesis in the hippocampus, and impairs spatial learning ability in rat pups [17].

In the present results, exposure to noise during pregnancy showed decreased neurogenesis and thickness in the motor and somatosensory cortex. In detail, noise decreased neurogenesis in layers II and III, layer IV, and layer V of the motor cortex and in layers II and III and layer IV of the somatosensory cortex. Noise also decreased layer thickness in layer I, layer IV, and layer V of the motor cortex and in layer I, layer IV, and layer V of the somatosensory cortex.

According to this study, neurogenesis and thickness were increased in the motor and somatosensory cortex of rat pups born from maternal rats exposed to music during pregnancy. By contrast, neurogenesis and thickness were decreased in the motor and somatosensory cortex of rat pups born from the maternal rats exposed to noise during pregnancy. It is known that adverse prenatal and early postnatal environment increase susceptibility to renal and metabolic dysfunction later in life [32]. Our study suggests that music and noise during the developmental period are important factors influencing brain development and urogenital disorders.

\section{CONFLICT OF INTEREST}

No potential conflict of interest relevant to this article was reported.

\section{ACKNOWLEDGEMENTS}

This work was supported by the National Research Foundation 
of Korea Grant funded by the Korean Government (MEST) (NRF-2010-0022895).

\section{REFERENCES}

1. Hayashi A, Nagaoka M, Yamada K, Ichitani Y, Miake Y, Okado N. Maternal stress induces synaptic loss and developmental disabilities of offspring. Int J Dev Neurosci 1998;16:209-16.

2. Lordi B, Patin V, Protais P, Mellier D, Caston J. Chronic stress in pregnant rats: effects on growth rate, anxiety and memory capabilities of the offspring. Int J Psychophysiol 2000;37:195-205.

3. Querleu D, Renard X, Versyp F, Paris-Delrue L, Crepin G. Fetal hearing. Eur J Obstet Gynecol Reprod Biol 1988;28:191-212.

4. Abbott A. Music, maestro, please! Nature 2002;416:12-4.

5. Zatorre R, McGill J. Music, the food of neuroscience? Nature 2005; 434:312-5.

6. Rauscher FH, Robinson KD, Jens JJ. Improved maze learning through early music exposure in rats. Neurol Res 1998;20:427-32.

7. Sutoo D, Akiyama K. Music improves dopaminergic neurotransmission: demonstration based on the effect of music on blood pressure regulation. Brain Res 2004;1016:255-62.

8. Foster NA, Valentine ER. The effect of auditory stimulation on autobiographical recall in dementia. Exp Aging Res 2001;27:215-28.

9. Pacchetti C, Mancini F, Aglieri R, Fundaro C, Martignoni E, Nappi G. Active music therapy in Parkinson's disease: an integrative method for motor and emotional rehabilitation. Psychosom Med 2000; 62:386-93.

10. Turner RP. The acute effect of music on interictal epileptiform discharges. Epilepsy Behav 2004;5:662-8.

11. Alladi PA, Wadhwa S, Singh N. Effect of prenatal auditory enrichment on developmental expression of synaptophysin and syntaxin 1 in chick brainstem auditory nuclei. Neuroscience 2002;114:577-90.

12. Secoli SR, Teixeira NA. Chronic prenatal stress affects development and behavioral depression in rats. Stress 1998;2:273-80.

13. Drago F, Di Leo F, Giardina L. Prenatal stress induces body weight deficit and behavioural alterations in rats: the effect of diazepam. Eur Neuropsychopharmacol 1999;9:239-45.

14. Rehm S, Jensen G. Aircraft noise and premature birth. J Sound Vib 1978;59:133-5.

15. Williams MT, Hennessy MB, Davis HN. Stress during pregnancy alters rat offspring morphology and ultrasonic vocalizations. Physiol Behav 1998;63:337-43.

16. Kruggel F, Bruckner MK, Arendt T, Wiggins CJ, von Cramon DY. Analyzing the neocortical fine-structure. Med Image Anal 2003; 7:251-64.
17. Kim H, Lee MH, Chang HK, Lee TH, Lee HH, Shin MC, et al. Influence of prenatal noise and music on the spatial memory and neurogenesis in the hippocampus of developing rats. Brain Dev 2006;28: 109-14.

18. Kim SE, Shin MS, Kim CJ, Park JH, Chung KJ, Jung H, et al. Effects of Tamsulosin on Urinary Bladder Function and Neuronal Activity in the Voiding Centers of Rats with Cyclophosphamide-induced Overactive Bladder. Int Neurourol J 2012;16:13-22.

19. Cho HS, Shin MS, Song W, Jun TW, Lim BV, Kim YP, et al. Treadmill exercise alleviates short-term memory impairment in 6-hydroxydopamine-induced Parkinson's rats. J Exer Rehabil 2013;9: 354-61.

20. Chen DG, Huang YF, Zhang JY, Qi GP. Influence of prenatal musicand touch-enrichment on the IQ, motor development, and behavior of infants. Chin J Psychol 1994;8:148-51.

21. Arabin B. Music during pregnancy. Ultrasound Obstet Gynecol 2002;20:425-30.

22. Gould E, Tanapat P. Stress and hippocampal neurogenesis. Biol Psychiatry 1999;46:1472-9.

23. Kadner A, Pressimone VJ, Lally BE, Salm AK, Berrebi AS. Lowfrequency hearing loss in prenatally stressed rats. Neuroreport 2006;17:635-8.

24. King S, Laplante DP. The effects of prenatal maternal stress on children's cognitive development: Project Ice Storm. Stress 2005;8:35-45.

25. King S, Mancini-Marie A, Brunet A, Walker E, Meaney MJ, Laplante DP. Prenatal maternal stress from a natural disaster predicts dermatoglyphic asymmetry in humans. Dev Psychopathol 2009;21:343-53.

26. Laplante DP, Brunet A, Schmitz N, Ciampi A, King S. Project Ice Storm: prenatal maternal stress affects cognitive and linguistic functioning in 5 1/2-year-old children. J Am Acad Child Adolesc Psychiatry 2008;47:1063-72.

27. Talge NM, Neal C, Glover V; Early Stress, Translational Research and Prevention Science Network: Fetal and Neonatal Experience on Child and Adolescent Mental Health. Antenatal maternal stress and long-term effects on child neurodevelopment: how and why? J Child Psychol Psychiatry 2007;48:245-61.

28. Beversdorf DQ, Manning SE, Hillier A, Anderson SL, Nordgren RE, Walters SE, et al. Timing of prenatal stressors and autism. J Autism Dev Disord 2005;35:471-8.

29. Kinney DK, Munir KM, Crowley DJ, Miller AM. Prenatal stress and risk for autism. Neurosci Biobehav Rev 2008;32:1519-32.

30. Grizenko N, Shayan YR, Polotskaia A, Ter-Stepanian M, Joober R. Relation of maternal stress during pregnancy to symptom severity and response to treatment in children with ADHD. J Psychiatry 
Neurosci 2008;33:10-6.

31. Li J, Olsen J, Vestergaard M, Obel C. Attention-deficit/hyperactivity disorder in the offspring following prenatal maternal bereavement: a nationwide follow-up study in Denmark. Eur Child Adolesc Psychiatry 2010;19:747-53.
32. Flynn ER, Alexander BT, Lee J, Hutchens ZM Jr, Maric-Bilkan C. High-fat/fructose feeding during prenatal and postnatal development in female rats increases susceptibility to renal and metabolic injury later in life. Am J Physiol Regul Integr Comp Physiol 2013; 304:R278-85. 